\title{
PROFESSIONALISM, POSTMODERN ETHICS AND THE GLOBAL STANDARDS FOR SOCIAL WORK EDUCATION AND TRAINING
}

\section{Vishanthie Sewpaul}

\section{INTRODUCTION}

The Global Standards for Social Work Education and Training (hereafter referred to as "the document") that was adopted by the General Assemblies of the International Association of Schools of Social Work (IASSW) and the International Federation of Social Workers (IFSW) in October 2004 was born out of several small and big compromises. As Chair of the Global Standards Committee, I remain ambivalent about some of the processes and the product. As pointed out previously (Williams \& Sewpaul, 2004), despite the best attempts at consultation and ensuring representation of different voices, they remained flawed, especially when working on a document that is supposed to cover worldwide processes and representation. On being asked to Chair the Global Standards Committee my reaction was that it was a preposterous and over-ambitious goal, with my biggest fear being that it would reinforce a Western hegemony and reproduce Western professional imperialism in social work education and practice. I was informed that because I understood the sensitivities and complexities of such an endeavour, I would be suited to lead the process.

We began with consultation with colleagues across the globe (see Sewpaul \& Jones, 2005 for details) on open questions such as: Should IASSW and IFSW engage in developing global standards for social work education and training? What did colleagues think about the idea of developing such standards? What might the purpose of such standards be? What sort of content should be included in such a document? What might the advantages of such standards be? What might the potential disadvantages be? Might such standards reinforce a Western hegemony?

I initially believed that my task would be an easy one - that the majority of our colleagues would reject the very idea of global standards and that I would write a report to IASSW indicating this and that my task would end there. To my surprise, however, apart from a few dissenting voices, the majority of those consulted enthusiastically embraced the idea. Thus began a four-year exciting but arduous process of developing the standards. For David Jones (who co-chaired the Committee as a representative of IFSW) and I, who were ultimately responsible for putting together the document, the task was an unenviable one. We had to make sense of directives and requests from different ends of the continuum. Some colleagues indicated that for such standards to have meaning, we must be specific enough to include prescribed reading ${ }^{1}$, credits and number of hours of study! On the other extreme, there were those who said there should be no standards whatsoever. The mandate, though, from the majority, in between the extreme ends of the spectrum, was that IASSW and IFSW develop standards that were broad enough to fit any context, but specific enough to be truly meaningful!

\footnotetext{
${ }^{1}$ I conjured up images of huge tensions and contests among European, American and Australian social workers [who currently dominate the literature base of social work] vying for first position in the prescription of texts on a global level! Given Western hegemony and the presumed superiority of the Global North and West, it would have been most unlikely that the marginalised voices of colleagues from the Global South and the East would have been considered worthy of inclusion.
} 
Through long hours of reflection, reading and dialogue with colleagues and friends, the idea finally gelled that we could have global standards (with the acknowledgement that the development of standards is inherently modernist in nature) recast within a postmodernist framework (Williams \& Sewpaul, 2004), and to have the standards framed as aspirational tenets rather than as narrow minimum standards that might jeopardise some schools of social work, especially in the developing world. In this article I revisit some of the modernist assumptions underlying the Global Standards document in relation to the notions of professionalism and codes of ethics. This is preceded by a brief elucidation of some of the key components of the document. I conclude with a critique of modernist assumptions of moral certainly founded in external rules and codes, and I call for "being for the Other" (Levinas, cited in Bauman, 1993) to be considered an ethical imperative in social work.

\section{KEY COMPONENTS OF THE GLOBAL STANDARDS DOCUMENT}

Acknowledging some of the criticism and limitations of the international definition of social work $^{2}$ (Sewpaul \& Jones, 2005; Yip, 2004), the document accepted the definition as it was adopted by the IFSW and IASSW as a point of departure. The Standards are located in alignment with the core purposes of social work, which range from advocacy, social activism and policy formulation to the protective and direct service delivery functions of the social worker. The first purpose reads: Facilitate the inclusion of marginalised, socially excluded, dispossessed, vulnerable and at-risk groups of people. ${ }^{3}$

The footnote to the first core purpose is characteristic of the document. It is extensively footnoted as we had to emphasise that certain concepts and words might have different meanings in different contexts. The document consistently iterates the importance of considering historical, political, socio-economic and cultural context-specific realities. The core purposes themselves stirred some controversy, even from colleagues within the same context. For example, while one colleague from Sweden saw the core purposes as too radical and claimed that if social workers worked toward them, they would be a threat to the system and be imprisoned, while another from Norway expressed the view that the core purposes were far too conservative.

The document (Sewpaul \& Jones, 2005) reflects a set of nine broad standards, each of which contains detailed sub-standards. The nine sets of standards relate to:

1) The school's core purpose or mission statement;

2) Programme objectives and outcomes;

3) Programme curricula, including fieldwork;

4) Core curricula including the domains of: the social work profession; the social work professional; methods of social work practice and paradigm of the social work profession;

\footnotetext{
2 The definition reads: "The social work profession promotes social change, problem solving in human relationships and the empowerment and liberation of people to enhance well-being. Utilising theories of human behaviour and social systems, social work intervenes at the points where people interact with their environments. Principles of human rights and social justice are fundamental to social work". It is currently under review, with IFSW and IASSW engaging in consultative processes to this end.

${ }^{3}$ Such concepts lack clear definition. Persons who fall into the categories of being "marginalised", "socially excluded", "dispossessed", "vulnerable" and/or "at risk" may be differently defined by individual countries and/or regions.
} 
5) Social work professional staff;

6) Social work students;

7) Structure, administration, governance and resources;

8) Cultural and ethnic diversity; and

9) Values and ethical codes of conduct for social work.

Given that the development of standards, by the very nature of standards, generally tends to fall within a prescriptive, reductionist, logical-positivist paradigm, efforts were made to adopt an alternative and a more empowering, non-prescriptive language in developing the global standards. The main aim was to enhance social work education, training and practice on a global level by facilitating dialogue within and across nations and regions. The document reflects standards that schools of social work should consistently aspire towards which, collectively and if met, might provide for quite sophisticated levels of social work education and training. The document has served to stimulate much debate, dialogue, research and publications from colleagues in different parts of the world - a desired outcome of the initiative. However, there are drawbacks, as discussed below.

\section{PROFESSIONALISM: A DOUBLE-EDGED SWORD IN SOCIAL WORK}

Social work was historically rooted in the ethos of caring, with early philanthropy being infused with religious injunctions to provide services for the most disadvantaged and marginalised members of society (Sewpaul, 2005). With industrialisation and urbanisation and the growing threats that the poor and unemployed represented to the elite, social work became inscribed with control functions and with protection of the middle class (Clarke, 1993). Born within the period of modernity, despite its competing strands with the Settlement House Movement of Jane Addams (Ife, 1997), social work began to take on the omniscient voice of science (Franklin, 1986; Howe, 1994; Ife, 1997). It is within this positivist scientific paradigm and culture of cure and control that the discipline of social work has seen its most pronounced development, but this has been a double-edged sword.

From its inception social work sought its legitimacy from other older professions such as medicine, law and theology. Abraham Flexner, who was considered a leading authority in medical education, identified specific criteria by which occupations might be distinguished from professions and at the 1915 National Conference of Charities and Corrections he concluded that social work was not a profession. "Professions engage in intellectual operations involving individual responsibility, derive their material from science and learning, work this material up to a practical end, apply it using techniques that are educationally communicable, are self-organised, and are motivated by altruism" (Flexner, cited in Popple, 1985:561). Mary Richmond challenged Flexner's view in 1917 through the publication of her book Social Diagnosis, which valorised casework that was modelled on the medical paradigm (Franklin, 1986) with its pathology-based focus on diagnosis, cure and control. Richmond was rewarded with an Honorary Masters degree for "establishing the scientific basis of a new profession" (Franklin, 1986:516). Thus, Volz (cited in Sewpaul \& Holscher, 2004:31) asserted, social work "[learned] the language of the powerful, those who matter and create identities, and [inscribed] itself into the legitimate and legitimising narratives of 'science' [and] progress". Sewpaul and Holscher (2004:31) go on to argue that "social work adopted with the language of 'skills', 'techniques' and 'diagnosis' a modern conceptualisation of its relationship with its clientele as one between the expert subject and his or her object". The dominance that social casework 
gained over its early alternatives (e.g. community-based initiatives via the Settlement House Movement) may be attributed to its ability to emulate the prevailing professional and scientific discourses of the time (Franklin, 1986). Social work aped the natural sciences in its striving for recognition, status and professionalism.

The earlier version of the title of the document (Sewpaul \& Jones, 2004) read "Global standards for social work education and training". The final version of the document as it appears in the International Journal of Social Welfare (Sewpaul \& Jones, 2005) reads: "Global Standards for the Education and Training of the Social Work Profession". During the process of developing the standards, our colleagues in the field of social pedagogy expressed concern that the document did not accommodate them as a separate entity and that it did not embrace a language that was inclusive of social pedagogy. In response to this the following was included in the earlier document, with respect to the universal-particular debate: " ... given the profession's historically fragmented strands; the contemporary debates around social work's intra-professional identity; its identity vis-à-vis other categories of personnel in the welfare sector such as social pedagogues, development workers, child care workers, probation officers and youth workers (where such categories of personnel are differentiated from social work); and the enormous diversities across nations and regions, there was some scepticism about the possibility of identifying any such "universal"' (Sewpaul \& Jones, 2004:503, my italics). We were of the view that this would have taken care of the concerns of the social pedagogues. However, at the Board meetings of the IFSW and IASSW in October 2004 in Adelaide, our social pedagogy colleagues were still dissatisfied. They agreed to the document being put forward for adoption at the General Assembly of IASSW on condition that the language that they provide will be incorporated into the review to reflect the inclusion of social pedagogy.

After many follow-up requests and delay, our social pedagogy colleagues responded asking for one major change throughout the document - that the title be altered from "Global standards for the education and training of social work" to "Global standards for the education and training of the social work profession" and that all references to "social work" in the document be changed to read "the social work profession". This called for a huge ideological shift. The dominant notion of professionalism - as opposed to the still marginalised postmodernist, emancipatory and feminist views on non-hierarchal, egalitarian relationships; worker involvement; subjectivities and relational ethics - derives from modernity's positivist embracing of factors such as detachment in "social worker-client" relationships, neutrality, the social worker as expert, aspirations toward scientific standards of truth, experimentation, universal laws, and the separation of the professional from the person. With regard to the latter point in particular, Bauman asserts:

[...] it does not always feel like that at all; not all stains incurred on the job - "in the course of the role performance" - stay on the work clothes alone. Sometimes we have the unsavoury feeling of some of the mud spilling on our body, or the fatigues sticking to our skin too tight for comfort; they cannot be easily peeled off and left behind the locker [...] Away from mere "role playing", we are indeed "ourselves", and thus we and we alone are responsible for our deeds. (Bauman, 1993:19)

The discomfort about respecting the views and recommendations from our social pedagogy colleagues was acute. However, having made the promise to accept the language that they provided meant that neither IASSW nor IFSW could go back on a principled decision. But in keeping our promise to the social pedagogues, mainly our counterparts from Denmark, we compromised our position in relation to the ethos that the document was intended to convey, 
and we angered some of our colleagues in Asia and other developing parts of the world, where social work is not yet seen to be a fully fledged profession. The title and the continuous references to "the social work profession" speaks to a betrayal of our consultation processes in that they minimised the voices of colleagues from the developing world and reflect a European, Western hegemony - precisely what we sought to guard against at all times! Akimoto (2007), for example, commented specifically on the document's emphasis on professionalism, asserting that it represented a Western unipolarity in social work education.

Yet, as Sakaguchi and Sewpaul (2009) indicated, the issues are more nuanced and complex. They point out that developing countries are often complicit in their emulation of the West, just as social work is complicit in trying to emulate the logical-positivist rationality of the natural sciences in its striving for status, prestige and professionalism. In comparing social work education across Japan and South Africa in relation to the global standards, Sakaguchi and Sewpaul conclude with the following:

All too often there is deference to the West as the gold standard. The complex systems of standards development and accreditation both in SA and Japan are Western imports; yet both countries appear to have enthusiastically and unreservedly acceded to the demands of Western professional legitimizing. Perhaps therein lay the crunch with the Global Standards, the international definition and the international code of ethics, all of which represent a universalizing discourse around what excellent social work ought to be. If IASSW and IFSW are perceived to be the authorized truths, then might it not become a self-imposition that national endeavours emulate global aspirations? (Sakaguchi \& Sewpaul, 2009:8).

There is a pattern in the literature that reflects a general paradox with Asian and African scholars critiquing Western hegemonic discourses, yet - all too often - embracing concepts, definitions, models and theories that derive from the West (Sen, 2005; Sewpaul, 2007). The voluntary co-option of developing countries into the dominant paradigms of the West is also reflected in the Global Standards with regard to ethical codes. Given the drive toward professionalism and that subscribing to a code of ethics is viewed as a core component of a profession, this standard was included in the document. In the following section the taken-forgranted assumption that codes of ethics contribute to ethical conduct is questioned. A particular focus of attention is the interrogation of the place of codes of ethics in relation to personal morality and "being for the Other" (Levinas cited in Bauman, 1993).

\section{POSTMODERN ETHICS AND CODES OF ETHICS}

Bauman (1993:3, my italics) asserts that the "postmodern approach to ethics consists [...] not in the abandoning of characteristically modern concerns, but the rejection of the typically modern ways of going about its moral problems (that is, responding to moral challenges with coercive normative regulation ...). The great issues of ethics - like human rights, social justice [...] - have lost nothing of their topicality. They only need to be seen, and dealt with, in a novel way". This accords with Leonard's (1999:14) thesis that postmodernism is "a cultural and political critique of the present [...] perhaps postmodernity is best understood as simply the latest stage of modernity in which we look back, from the present, and are critical in a new way about the trajectory by which we arrived at the present".

Bauman (1993:9) goes on to argue that "the moral thought and practice of modernity was animated by the belief in the possibility of a non-ambivalent, non-aporetic ethical code". Postmodernism lays bare the disbelief of such a possibility and points to the misguided efforts 
of modernity. Hence Bauman's (1993:10) cogent assertion that "The foolproof - universal and unshakably founded - ethical code will never be found [...] a non-aporetic, non-ambivalent morality, an ethics that is universal and 'objectively founded', is a practical impossibility; perhaps also an oxymoron, a contradiction in terms". The complexities of moral dilemmas that we face in our contemporary world cannot be dealt with by a reliance on ethical codes.

Yet in continuation of modernity's great projects of perfecting the performance of nature along progressively rational lines (science) and judging human conduct (ethics) (Howe, 1994), codes of ethics abound in social work, with IFSW having it as one of the pre-requisites for affiliation. It has become a taken-for-granted assumption that such codes constitute the cornerstone of professionalism and that they enhance ethical conduct. In accordance with such a norm, the Global Standards document details requirements in respect of ethical conduct, registration of social workers and disciplinary measures to be taken against social workers should they violate the codes of ethics (Sewpaul \& Jones, 2005). Bauman (1993:20) speaks of our reliance on rules and how this detracts from individual responsibility. "Relying on the rules has become a habit, and without the fatigues we feel naked and helpless [...], we miss responsibility badly when it is denied to us, but once we get it back it feels like a burden too heavy to carry alone". Citing Erich Fromm, Bauman (1993:20, my italics) concludes that "in our effort to escape from aloneness and powerlessness, we are ready to get rid of our individual self either by submission to new forms of authority or by compulsive conforming to accepted patterns". Bauman (in Bauman \& Tester, 2001:51) contends: "If freedom is a value, it is also an utterly ambivalent one. It attracts and repels at the same time". Following the rules and codes might in some instances produce more harm than good. Under apartheid and Nazi Germany, for example, many atrocities against humanity were committed by those who did the bidding of the state and followed the rules and codes of conduct to perfection.

The details with regard to ethical codes vary across countries. Sakaguchi and Sewpaul (2009) detail the differences in approach regarding registration of social workers and the coercive approaches used in disciplinary action in South Africa compared with that of Japan. They conclude that this does raise the question about the role and place of codes of ethics with respect to the moral impulse (Hölscher \& Sewpaul, 2006; Husband, 1995). Do or can such codes ensure ethical conduct? Should we presume that the absence of disciplinary practices in Japan contributes to less ethical practices among Japanese social workers? It might be argued that regulatory disciplinary measures reinforce the system-stabilising functions of social work. In South Africa, for example, a social worker might be called up for disciplinary action if an individual case is not followed through, or if case records are not properly kept. There is no such threat for social workers who do not challenge the structural barriers that maintain people in poor, unemployed and unhealthy circumstances. Social work's normalising function has remained its defining feature across the globe and through decades. Inevitably ethical tensions arise from social work's positioning as mediator between the powers that be and those who are marginalised (Sewpaul \& Hölscher, 2004).

These tensions are rooted in the contradiction between the profession's moral legitimacy which is derived from empathetic, dialogical and democratic relationships that may emerge in encounters with service users, and from an understanding of the impact of structural factors on people's lives, and from its societal legitimacy, which is derived from fulfilling social work's ameliorative and normalising functions (Hölscher \& Sewpaul, 2006). The latter favours social workers who are disengaged and ignorant of structural forms of injustice and oppression. It requires "social handywomen [who do] many kinds of repairs ... to the living conditions and 
personal attitudes of citizens" (Epstein, 1999:7). The former calls for critical reflection on the exact nature of those structures that marginalise social work's service users and on social work's complicity in this regard. From a system-stabilising point of view, it makes sense to regulate and monitor the profession so as to ensure the handiwork is done and to reduce the notion of ethical practice to merely following pre-formulated codes and rules (Hölscher \& Sewpaul, 2006).

The neoliberal and new managerial onslaught in social work is manifest in an increasing production and dissemination of quality standards, codes of ethics, procedural manuals and assessment schedules. These have contributed to shifts from possible constructionist, emancipatory and radical approaches in social work to resource management, cost-efficiency and administration (Sewpaul and Hölscher, 2004). The result is "at best ... bureaucratic practice ... and at worst ... defensive practice" (Banks, 2001:154-155).

The South African (SA) Code of Ethics (www.sacssp.co.za) - a 72-page document which reinforces morality as nothing other than a social contract - leaves no room for ambivalence, ambiguity of being, freedom to deal with ethical plurality and the messiness of real life (as postmodern ethicists would call for) as it even legislates on love! In what it refers to as "dual relationships" the SA Code reads:

The social worker should not be involved in relationships that compromise the social work relationship. If such a dual relationship develops or is discovered after the social work relationship has been initiated, the social worker should terminate the social work relationship in an appropriate manner. He/she should notify the client in writing of the termination, assist the client to obtain services from another social worker and should not engage in any self-enhancing relationship with the client until at least twenty-four months has lapsed after the termination. ${ }^{4}$ [My italics]

The above is an example of our search for moral certainty in prescriptive rules and codes as opposed to Bauman's call to re-personalise morality. Given the prescriptive code and regulations of the South African Council for Social Service Professions (SACSSP) and the disciplinary functions that it serves, it is not surprising that social workers are reluctant to rely on their own judgments and that they turn to the SACSSP for guidance and rules as to how to perform their day-to-day tasks. Out of fear of making mistakes and being called up for disciplinary action, there are social workers who want the SACSSP to tell them what to do and how to do things under specific circumstances. This sets in motion a vicious cycle - the more social workers do this, the more prescriptive the code and the regulations of the SACSSP become; the more prescriptive the code becomes, the greater the fear among social workers, and the greater the fear, the more the deference is shown to the SACSSP for rules of conduct. The more a social worker relies on the external code, the less likely he/she is to rely on his/her own sense of morality, thus making them less likely to struggle and work through complex moral dilemmas and ethical decision-making. Yet, as Bauman (1993:34) asserts, it is "personal morality that makes ethical negotiation and consensus possible, not the other way round". Thus Bauman calls on us to deal with ambiguity of being and on our willingness to be for the Other, as the centre of postmodern ethics - the benefits of which he describes as follows:

\footnotetext{
${ }^{4}$ This does mean, for example, that if a social worker falls in love with a client and is willing to give up his/her job to pursue the relationship, he/she cannot do so for two years following the termination of the social work relationship. It also raises questions about what happens if the "client system" is a community - does this preclude the social worker from having a relationship with anyone from that defined community?
} 
Acceptance of contingency and respect for ambiguity do not come easy; there is no point in playing down their psychological costs. And yet the silver lining for this particular cloud is uncommonly thick. The postmodern re-enchantment of the world carries a chance of facing human moral capacity point-blank, as it truly is, undisguised and undeformed; to readmit it to the human world from its modern exile, to restore it to its rights and dignity; to efface the memory of defamation, the stigma left my modern mistrust [...] Perhaps starting from there [...] will even make the hope of a more humane world more realistic. (Bauman (1993:34)

\section{CONCLUSION}

Williams and Sewpaul (2004) acknowledged that the specification of criteria in the Global Standards document, albeit in the form of ideals to be aspired toward, falls within a reductionist, modernist mode of thinking. In writing the article Williams and I asked the following question: "Are we in modernist fashion continuing the 'discourse of legitimation' (Lyotard, 2003:259) in respect of the status of social work?" Five years down the line and with the benefit of hindsight, I believe the Global Standards document might be serving this end. In the appendix to the document Sewpaul and Jones (2005:227) claim that: "The document is not intended to be a fixed timeless product; it is a dynamic entity subject to review and revision as and when the need arises." The discourse on legitimation may not in itself be the problematic; it is the modernist discourse on legitimation and all that it has come to mean in relation to logical-positivist rationality, professionalism and codes of ethics, as I discuss in this paper, that require critical interrogation, and it is perhaps time to revisit some of the inherent modernist assumptions underlying the Global Standards document.

Given the birth of social work during the period of modernity with its emphasis on reductionist logical-positivist rationality, it is not surprising that it took on this dominant discourse in the pursuit of status and professionalism. To this end we have seen codified systems of ethics, the move towards greater standardisation and competencies development (Dominelli, 1996, 2004), systems of accreditation, and a proliferation of managerial and market discourses in welfare (Dominelli, 2004; Ife 1997; Sewpaul \& Hölscher, 2004) and an increase in the development and use of professional jargon. It is these concerns that dogged me at the inception of formulating the Global Standards, and they continue to bother me when I reflect on some of the processes and the final product of the Global Standards.

Rather than having a code of ethics as the normative in social work, should we not be asking the following questions: Is the source of ethical practice within or outside the self? Does the question itself pose a false dichotomy? Is the relationship between the internal and external origins of morality more complex than it appears? How do we make sense of Kant's view that freedom of self (the rational autonomous self) is the precondition of moral action, as opposed to Levinas's view that freedom of self is the product of moral responsibility to the Other which, according to Bauman, is inherently irrational? This does raise the question of autonomy versus obligation to the Other as the foundation for everyday ethical practice. Rather than having a prescriptive codes of ethics with regulatory and coercive mechanisms, might social work not benefit from a few broad statement of principles that provide greater space for critical engagement and dialogue about issues that produce ethical dilemmas in our daily practice?

Instead of our emphasis on external codes of ethics, should we consider making responsibility for, and "being for" the Other (Bauman, 1993; Bauman \& Tester, 2001) normative in social work? Given the essentially asymmetrical nature of such relationships, would we bear the risk 
of minimising and patronising the Other in social work relationships? The appeal of such an approach lies in Bauman's (1993) assertion that the moral self accords the unique Other that priority assigned to the self. The justification for the self, for Levinas (cited in Bauman, 1993), begins with the Other; our responses to the call of the Other define us. Thus Bauman's emphasis on meeting with the stranger - the Other as Face - not as persona, the mask worn to signify the role played. Drawing on the ethical theory of Levinas, Bauman concludes:

The Face is not a force. It is an authority. Authority is often without force [...] The absolute nakedness of a face, the absolutely defenseless face, without covering, clothing or mask, is what opposes my power over it, my violence [...] By herself the Other is weak, and it is precisely that weakness that makes my positioning of her as the Face a moral act: I am fully and truly for the Other, since it is I who gave her the right to command, make the weak strong, make the silence speak, make the non-being into being through offering it the right to command me. "I am for the other" means I give myself to the Other as hostage [...] It is I who take the responsibility [without a contract or obligations] [...] My responsibility, which constitutes, simultaneously, the Other as the Face and me as the moral self, is unconditional. (Bauman, 1993:73-74)

\section{REFERENCES}

AKIMOTO, T. 2007. The unipolar world and inequality in social work: a response to James Midgley. Global inequality, power and the unipolar world: implications for social work. International Social Work, 50(5):686-690.

BANKS, S. 2001. Ethics and values in social work ( $2^{\text {nd }}$ ed). Houndmills, Basingstoke, Hampshire: Palgrave.

BAUMAN, Z. \& TESTER, K. 2001. Conversations with Zygmunt Bauman. Oxford: Polity Press.

BAUMAN, Z. 1993. Postmodern ethics. Oxford: Blackwell Publishing Ltd.

CLARKE, J. 1993. The comfort of strangers: social workers in context. In: CLARKE, J. (ed) A crisis in care? Challenges to social work. London, Newbury Park, New Delhi: Sage Publications.

DOMINELLI, L.D. 1996. Deprofessionalizing social work: anti-oppressive practice, competencies and postmodernism. British Journal of Social Work. 26:153-175.

DOMINELLI, L.D. 2004. Social work: theory and practice for a changing profession. Cambridge: Polity Press.

EPSTEIN L. 1999. The culture of social work. In: CHAMBON, A.S., IRVING, A. \& EPSTEIN, L. (eds) Reading Foucault for social work. New York: Columbia University Press.

FRANKLIN, D.L. 1986. Mary Richmond and Jane Addams: from moral certainty to rational inquiry in social work practice. Social Service Review, 504-521.

HÖLSCHER, D. \& SEWPAUL, V. 2006. Ethics as a site of resistance: the tension between social control and critical reflection. In: HALL, N. (ed) Social work: making a world of difference. Berne: IFSW \& Fafo.

HOWE, D. 1994. Modernity, postmodernity and social work. British Journal of Social Work, 24:513-532. 
HUSBAND, C. 1995. The morally active practitioner and the ethics of anti-racist social work. In: HUGMAN, R. \& SMITH, D. (eds) Ethical issues in social work. London, New York: Routledge.

HUTCHINGS, A. \& TAYLOR, I. 2007. Defining the profession? Exploring an international definition for social work in the China context. International Journal of Social Welfare, 16:381-389.

IFE, J. 1997. Rethinking social work: towards critical practice. Melbourne: Longman.

JIA, C. 2007. Correcting misconceptions about the development of social work in China: a response to Hutchings and Taylor. International Journal of Social Welfare, 16:98-101.

LEONARD, P. 1999. Postmodern welfare. Reconstructing an emancipatory project. London, Thousand Oaks, New Delhi: Sage Publications.

LYOTARD, J.F. 2003. From the postmodern condition: a report on knowledge. In: CAHOONE, L. (ed) From modernism to postmodernism: an anthology. Oxford: Blackwell Publishing Ltd.

POPPLE, P.R. 1985. The social work profession: a reconceptualisation. Social Services Review, December:560-574.

SAKAGUCHI, H. \& SEWPAUL, V. 2009. A comparison of social work across Japan and South Africa in relation to the global standards for social work education and training. International Journal of Social Welfare, 18:1-11.

SEN, A. 2005. The argumentative Indian: writings on Indian culture, history and identity. London: Penguin Books.

SEWPAUL, V. \& HOLSCHER, D. 2004. Social work in times of neoliberalism: a postmodern discourse. Pretoria: Van Schaik Publishers.

SEWPAUL, V. \& JONES, D. 2004. Global standards for social work education and training. Social Work Education, 23(5):493-513

SEWPAUL, V. \& JONES, D. 2005. Global standards for the education and training of the social work profession. International Journal of Social Welfare, 14(3):218:230.

SEWPAUL, V. 2005. Global standards: possibilities and pitfalls for re-inscribing social work into civil society. International Journal of Social Welfare, 14(2):210-217.

SEWPAUL, V. 2007. Challenging East-West value dichotomies and essentialising discourse on culture and social work. International Journal of Social Welfare, 16:398-407.

SOUTH AFRICAN COUNCIL FOR SOCIAL SERVICE PROFESSIONS. 2004. Code of Ethics Guidelines. Pretoria: SACSSP. [Online] Available: www.sacssp.co.za.

WILLIAMS, L.O. \& SEWPAUL, V. 2004. Modernism, postmodernism and global standards setting. Social Work Education, 23(5):555-565.

YIP, K. 2004. A Chinese cultural critique of the global qualifying standards for social work education. Social Work Education, 23(5):597-612.

Prof Vishanthie Sewpaul, School of Social Work and Community Development, University of KwaZulu-Natal, Howard College Campus, Durban, South Africa. 